\title{
French People's Views on the Appropriateness of Disclosing an Unsolicited Finding in Medical Genetics: A Preliminary Study*
}

\section{Puntos de vista de franceses respecto a lo apropiado de revelar hallazgos no solicitados en medicina genética: Un estudio preliminar}

\begin{abstract}
MARION Rosier
Université de Toulouse (UT2J), Francia

ORCID: http://orcid.org/0000-0002-3080-2974

Myriam Guedj ${ }^{\mathrm{a}}$

Université de Toulouse (UT2J), Francia

ORCID: http://orcid.org/0000-0002-8855-1266

Patrick Calvas

Hôpital de Purpan, Francia

ORCID: http://orcid.org/0000-0002-7293-3382

Sophie Julia

Université Toulouse III - Paul Sabatier, Francia

ORCID: http://orcid.org/0000-0003-1272-528X

Christelle Garnier

Hôpital de Purpan, Francia

ORCID: http://orcid.org/0000-0002-6522-8650

Anne CAmbon-Thomsen

Université Toulouse III - Paul Sabatier, Francia

ORCID: http://orcid.org/0000-0001-8793-3644

Maria Teresa Muñoz Sastre

Université de Toulouse (UT2J), Francia

a Correspondence author. E-mail: guedj@univ-

tlse2.fr

How to cite: Rosier, M., Guedj, M., Calvas, P., Julia, S., Garnier, C., Cambon-Thomsen, A., \& Muñoz Sastre, M. T. (2018). French People's Views on the Appropriateness of Disclosing an Unsolicited Finding in Medical Genetics: A Preliminary Study. Universitas Psychologica, 17(4), 1-11. https://doi.org/10.11144/Ja veriana.upsy17-4.fpva
\end{abstract}

\begin{abstract}
With progress in medical genetics, genome-sequencing techniques are becoming more and more efficient. However, these genetic tests may lead to the detection of unsolicited genetic findings, i.e. findings that are not the primary purpose of the screening. New ethical issues have emerged, in particular the question of whether to disclose these unsolicited findings to the patient or not. Forty-seven patients under supervision in a Medical Genetics service, 15 health professionals and 107 members of the French general population expressed their opinion regarding the appropriateness of disclosing an unsolicited high penetrance genetic finding in 36 scenarios containing three pieces of information on: a) patient information and consent;b) possibility of prevention and treatment of the detected genetic disease; and c) disclosure of the results by the physician (e.g., no disclosure of the unsolicited results). Four positions were found that were called Respect for patient's autonomy, Beneficence to patient, Non-maleficence, and Always appropriate.
\end{abstract}

Keywords 
France; medical genetics; unsolicited findings; patient disclosure.

\section{RESUMEN}

Con el progreso en medicina genética, las técnicas de secuencias de genomas están volviéndose más eficientes. Sin embargo, estos test genéticos pueden llevar a la detección de hallazgos no solicitados, e.g., hallazgos que no son el propósito primario del escaneo. Nuevos problemas éticos han surgido, en particular la pregunta de si revelar o no estos hallazgos no solicitados al paciente. 47 Pacientes bajo supervisión en un servicio de Medicina Genética, 15 profesionales de la salud y 107 miembros de la población general francesa, expresaron su opinión respecto a lo apropiado de revelar un hallazgo genético no solicitado de alto efecto en 36 escenarios con 3 piezas de información sobre: a) información del paciente y consentimiento, b) posibilidad de prevención y tratamiento de la enfermedad genética detectada, y c) revelación de los resultados por parte del médico (e.g., no revelar de los resultados no solicitados). Se encontraron cuatro posiciones que fueron llamadas Respeto por la autonomía del paciente, Beneficencia al paciente, No-maleficencia, y Siempre apropiado.

Palabras clave

Francia; medicina genética; hallazgos no solicitados; revelación al paciente.

The recent application of new technologies in medical genetics has led to the possibility of discovering "a finding concerning an individual [research] participant that has a potential health or reproductive importance" when conducting a genetic test (Wolf et al., 2008). In some cases, however, the current state of medical knowledge makes these findings difficult to interpret. Many terms are used to characterise this type of finding (e.g., incidental, secondary). The term "unsolicited finding" seems to be the most suitable given that the data are generated in a context of genetic technologies that are not related to the initial aim of the test (van El et al., 2013). This additional genetic information involves ethical and legal challenges in the clinical setting (Lolkema et al., 2013; Ormond et al., 2010).

The following example presents a realistic case highlighting the challenges faced by the physician: "In Mrs Thomas's family, many of the women are suffering or have suffered from breast cancer. In order to detect her risk of carrying the gene responsible for developing this type of cancer, she decided to take a genetic test. The laboratory used a new generation sequencing test that, in addition to revealing risk of cancer, is able to reveal other genetic risks not necessarily related to breast cancer. In Mrs. Thomas case, an unexpected anomaly involved in the development of heart disease has also been detected. What should the doctor do? Does he/ she have the legal and/or ethical duty to disclose this information to Mrs Thomas or to keep silent about this information?"

\section{Ethical and legal framework}

Currently, there is no international consensus about whether to disclose unsolicited findings to patients. Certain recommendations have, however, been made.

According to the American College of Medical Genetics and Genomics (ACMG), some genes and types of variants "should be examined and the results reported to the ordering clinician" (Green, Berg, et al., 2013). These are genes and types of variants featuring on a minimum list of 56 genes that are actively searched for during the sequencing and that should be disclosed to the patient. This recommendation is grounded on the beneficence principle suggested by Beauchamp and Childress (2001). It has been criticized by some professionals (Roche \& Berg, 2015; Wolf, Annas, \& Elias, 2013) who consider that these findings can be viewed as "not so-unsolicited" in that they are actively sought out (Allyse \& Michie, 2013). Furthermore, patients' autonomy could be undermined when laboratories look for those specific variants and put the information on the patient's medical record, even if the patient has expressed his/her wish not to be informed of unsolicited findings (Green, Lupski, $\&$ Biesecker, 2013). These recommendations have been updated and laboratories now have to actively look for 59 (not 56) secondary variants when carrying out genomic sequencing (Kalia et al., 2017). 
In Europe, the disclosing of unsolicited findings is framed by legislation and recommendations. At the legislative level, "individuals have access to all data that is collected about their health": this is the right to know. This right is accompanied by the right not to know, where individuals exercise their right of "not knowing about certain aspects of their health" and where health providers must respect with this wish (Ploem, 2014). The European Society of Human Genetics (ESHG) issued somewhat different recommendations (van El et al., 2013): It recommended minimising the likelihood of detecting unsolicited findings when performing genetic testing. ESHG also emphasised patients' autonomy: if patients want the unsolicited information, professionals should disclose this information to them; if they do not want to know, professionals should keep this information undisclosed (van El et al., 2013). This position refers to the principle of autonomy suggested by Beauchamp and Childress (2001): Health professionals must inform the patient and respect his decision even if it is questionable from a medical point of view.

In France, following the recommendations by the French National Authority for Health and the Bio-Medicine Agency, which stated that unsolicited known variants should be disclosed, a legal framework was set up (Haute Autorité de Santé, 2013). It is up to the physician to determine on a case-by-case basis and with the patient's express consent whether to disclose the unsolicited findings or not (Journal officiel de la République Française, 2013). Consequently, their application in the clinical setting may be difficult for genetic professionals and patients.

\section{Professionals', patients' and the general public's perspectives}

In the literature, many arguments are put forward in favour of or against the disclosure of unsolicited findings, often in relation to the ethics principles.

For instance, respect for autonomy is often cited in the literature. Indeed, there is a consensus among professionals on two main points: informed - even if challenging - consent must be offered to patients (Rigter et al., 2014), and disclosure depends on the patient's choice as "it is absolutely their right to choose" (Downing, Williams, Daack-Hirsch, Driessnack, \& Simon, 2013). Few studies deal with the views of the general public about disclosing unsolicited findings. They advocate, however, that the right to know should lead to disclosure (Regier et al., 2015; Townsend et al., 2012). As for patients, they often consent to the disclosure of all available unsolicited findings (Shahmirzadi et al., 2014).

The principle of beneficence is mentioned, especially among most professionals who agree that unsolicited findings should be disclosed when they could cause serious and medically actionable conditions, in terms of treatment or prevention (Berg, Khoury, \& Evans, 2011; Christenhusz, Devriendt, \& Dierickx, 2013; Lemke, Bick, Dimmock, Simpson, \& Veith, 2013; Lohn, Adam, Birch, Townsend, \& Friedman, 2013; Yu, Harrell, Jamal, Tabor, \& Bamshad, 2014). There is less consensus as to whether unsolicited findings involved in the development of serious but untreatable conditions should be disclosed to patients (Green et al., 2012; Lemke et al., 2013). Members of the general public consider that the possibility of prevention and treatment (medical actionability) and the seriousness of the condition should lead to disclosure (Regier et al., 2015; Townsend et al., 2012). Patients mention that being informed of the kind of discovery could improve patient quality of life (even when treatment options for the condition are limited), and help them prepare and plan their future. However, their consent to the disclosure of all available incidental findings diminishes when they learn about the different kinds of information they could receive, such as the fact that there is no available treatment for the condition in question (Bijlsma et al., 2017).

The previous point refers to the principle of non-maleficence (Beauchamp \& Childress, 2001). Another argument that refers to this principle is that, when the unsolicited findings are presumed or known to be benign, or if current 
medical knowledge does not enable the findings to be interpreted, they should be ignored (Berg et al., 2011; Christenhusz et al., 2013). The other major consideration for non-disclosure is the potential risk of psychological harm induced by the disclosure of findings, such as anxiety and possible discrimination (Downing et al., 2013; Townsend et al., 2012). Psychological issues such as emotional burden, anxiety and suffering from discrimination are often cited to explain their patients' preference for non-disclosure (Bijlsma et al., 2017; Clift et al., 2015).

\section{The present study}

The present study was motivated by the fact that even within the existing ethical and legal frameworks, disclosing unsolicited findings to patients "places a large burden on the clinicians to decide what information is appropriate to share" (Hehir-Kwa et al., 2015). Little research has been completed on the different perspectives of professionals, patients and the general public on the disclosure of unsolicited findings from genetic research (Middleton et al., 2015) and in the clinical setting (Townsend et al., 2012).

In the present study, realistic scenarios were constructed in order to determine the circumstances under which the disclosure and the withholding of unsolicited findings may pose a moral problem.

This preliminary study deals only with diseases for which known unsolicited findings had a high penetrance, i.e. when the genetic mutation was present, and the patient had a very high risk of developing the associated disease. We expected to find at least three different positions. The first hypothesized position would be to respect the patients' wishes and to respect a person's right to know and right not to know, as recommended by the European Society of Human Genetics (van El et al., 2013; Downing et al., 2013). This refers to the respect for autonomy. The second position would be to disclose all the information to patients on the ground that it is in their interest to be informed (beneficence to patient). Finally, the third position would be an intermediate position between the first two; that is, to respect patients' wishes when they consented to disclosure, and giving precedence to the beneficence principle when they were not informed or did not consent, except if the disclosure did more harm than good (nonmaleficence).

\section{Method}

\section{Participants}

Three different samples have been constituted $(N=169)$ : a) people from the general public; b) patients under supervision in a Medical Genetics unit; and c) genetic health professionals. People from the public (70 women, 37 men) were recruited in the city of Toulouse and the Occitania region in the south of France. They were 20-72 years old $(M=37.47, S D=14.19)$. The patients under supervision (27 women, 20 men) were recruited in the Medical Genetics unit of the hospital of Toulouse and were aged 18-72 years $(M=43.04, S D=17.42)$. The genetic health professionals were recruited in several Medical Genetics units in different hospitals in France. This sample comprised 15 physicians aged 31-58 years $(M=40.33, S D=10.59)$. Table 1 shows additional demographic information.

\section{Material}

The material was in French. It comprised 36 cards with a scenario, a question, and a response scale. These scenarios were constructed according to a three within-subject factor design combining three factors -- borrowed from previous studies:

a) patient information and consent about discovering potential unsolicited findings (was not informed of the possibility of discovering unsolicited findings, was informed of this possibility but did not consent to have the unsolicited results disclosed, was informed of this possibility and consented to have the unsolicited results disclosed); 
b) unsolicited disease prevention and treatment (available prevention and treatment, no prevention but available treatment, available prevention but no treatment, no prevention nor treatment); and

c) the doctor's decision (did not disclose the unsolicited information to the patient, disclosed part of the unsolicited information to the patient, disclosed all the unsolicited information to the patient), $3 \times 4 \times 3$.

In each scenario, certain information was held constant: each story concerned a 32-year-old woman who initially consulted for a genetic predisposition for breast cancer. The penetrance of the genetic mutation was also held constant, i.e. the unsolicited genetic mutation had a high penetrance and almost certainly predisposed the patient to developing the disease in question.

An example of a scenario is the following: "Mrs. Solier is 32. She is aware that in her family, many women over several generations have suffered from breast cancer. Her family doctor advised her to take a genetic test to assess her risks for breast cancer. This kind of test gives information on risks for breast cancer but it also gives information concerning other present and future health aspects. Mrs. Solier has not really been informed that this kind of test could also provide information on her health that is not necessarily directly related to breast cancer. Mrs. Solier follows her family doctor's advice and takes the test. The test reveals the expected information on the risk for breast cancer. It also reveals that Mrs. Solier suffers from genetic anomalies that almost certainly predispose her to malignant hyperthermia. This disease - occurring in crisis form - can be lethal even if it is caught in time but there is an easy way to prevent it: avoiding certain types of medicine, particularly those used in anaesthesia. With the results, the geneticist doctor-counsellor informs Mrs. Solier about the possibility that she may suffer from breast cancer. He also decides, however, to disclose part of the information concerning the other risks to her. To what extent do you think that the doctor-counsellor's behaviour is appropriate? Ratings were given on the 11-point appropriateness scale.

\section{Procedure}

After being informed of the aim of the study, each participant signed an informed consent, co-signed by the investigator. Information concerning the diseases mentioned was given to participants from the patient and general public groups. Participants were interviewed in various places. People from the general public were interviewed in public places such as a library, a vacant classroom at the university or the participant's home. Patients were interviewed in an empty dedicated room in the Medical Genetics Unit, in Toulouse. Professionals were interviewed in the hospital conference room or in their office.

As recommended by Anderson (1996, 2016), the session took place in two phases, a familiarization and an experimental phase. In the familiarization phase, the investigator explained the study with a certain number of scenarios. Participants were allowed to look back at the cards and to change their responses. During the second phase - the experimental phase participants had to rate all the 36 scenarios and were no longer allowed to look back at the other cards. After each phase, the investigator verified that participants were able to understand what was expected from them.

Only one session was necessary and it took 30-45 minutes to complete the entire material (familiarization and experimental phases). The familiarization phase helped participants to accomplish the experimental phase because they were accustomed to the material and to what was expected from them. None of the participants had trouble in filling out the questionnaires. The Ethics Committee of the University of Toulouse approved the study.

\section{Results}

A cluster analysis was performed on the raw data; four clusters were identified. These clusters are 
shown in Figure 1. ANOVAS were performed on the data from each cluster. Main results are shown in the Appendix.

Cluster 1 was the expected "Respect for patient's autonomy" cluster. It included 40 participants, almost a quarter of our participants (23.7\%): 22 people from the general population, 10 patients and 8 health professionals. In this cluster, the only factor with a significant main effect was the doctor's decision. The strongest interaction was Consent $\mathrm{x}$ Doctor's decision. If the doctor's decision corresponded to the patient's wish, the decision was highly appropriate (the mean value was above 8/10). In contrast, the decision was deemed not very appropriate if it did not correspond to the patient's wish or if the doctor only gave part of the information.

Cluster 2 was the expected "Beneficence to patient". It included 65 participants (38.5\%): 46 participants from general population, 18 patients and 1 professional. All factors had a significant effect, but the strongest factor was Doctor's decision. Participants in this group considered that it was highly appropriate to disclose all the information to the patient, even if the patient expressed the desire not to know. It was judged less or not at all appropriate to disclose part of or none of the information.
Figure 1

Patterns of results corresponding to the four clusters.

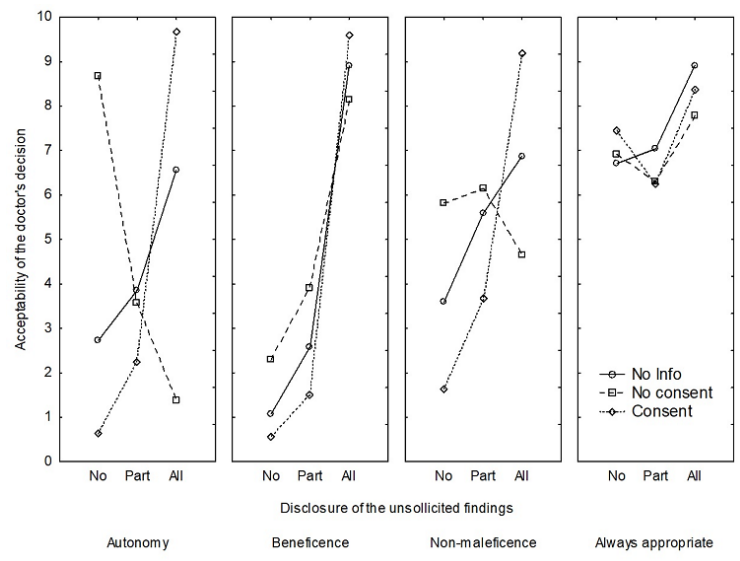

Note. From left to right: Respect for patient's autonomy, Beneficence to patient, Nonmaleficence, Always appropriate. The three curves express the patient's information and consent. The appropriateness assessment is on the $\mathrm{y}$-axis. The doctor's decision is on the $\mathrm{x}$-axis. "No", "Part" and "All" respectively correspond to the three modalities of the factor "Doctor's decision": do not disclose the incidental findings (IF) to the patient, disclose part of the IFs to the patient and disclose all the IFs to the patient

Cluster 3 was the expected "Nonmaleficence". It included 58 participants (34.3\%): 37 participants from the general population, 15 patients and 6 professionals. This cluster was, in some way, intermediate between the two previous ones. Participants judged the doctor's decision to be more appropriate when it was in accordance with the patient's wishes and when the disease was preventable and treatable (actionable). Nevertheless, when the disease was not actionable, they considered it more appropriate not to disclose the findings to the patient. Alone, the Prevention/treatment factor did not have a significant effect, but it did when combined with other factors, especially with Doctor's decision. This interaction has more weight, compared with the other clusters.

Cluster 4 was not expected. It was named "Always appropriate" and included 6 participants (3.6\%): 2 from the general population and 4 patients. The doctor's decision was considered to be always appropriate, no matter what he decided to disclose to the patient (mean $=7.3 / 10)$. These 
participants seemed to trust the doctor's decision. No factor had a significant effect.

\section{Table 1}

Composition of Clusters

\begin{tabular}{|c|c|c|c|c|c|}
\hline & Autonomy & Beneficence & $\begin{array}{c}\text { Non- } \\
\text { maleficence }\end{array}$ & $\begin{array}{c}\text { Always } \\
\text { Appropriate }\end{array}$ & $N$ \\
\hline \multicolumn{6}{|l|}{ Population } \\
\hline General public & $22(21)^{\mathrm{a}}$ & $46(43)^{\mathrm{a}}$ & $37(35)$ & $2(2)^{\mathrm{a}}$ & 107 \\
\hline Patients & $10(21)^{b}$ & $18(38)^{b}$ & $15(32)$ & $4(9)^{\mathrm{a}}$ & 47 \\
\hline Professionals & $8(53)^{\text {ab }}$ & $1(7)^{\mathrm{ab}}$ & $6(40)$ & 0 & 15 \\
\hline \multicolumn{6}{|l|}{ Gender } \\
\hline Male & $13(21)$ & $26(41)$ & $22(35)$ & $2(3)$ & 63 \\
\hline Female & $27(25)$ & $39(37)$ & $36(34)$ & $4(4)$ & 106 \\
\hline \multicolumn{6}{|l|}{ Age } \\
\hline 18-30 Years & $18(29)$ & $22(35)$ & $21(33)$ & $2(3)$ & 63 \\
\hline 31-45 Years & $13(27)$ & $15(31)$ & $21(43)$ & 0 & 49 \\
\hline 46-60 Years & $5(14)$ & $19(53)$ & $10(28)$ & $2(6)$ & 36 \\
\hline $61+$ Years & $4(19)$ & $9(43)$ & $6(29)$ & $2(10)$ & 21 \\
\hline \multicolumn{6}{|l|}{ Marital Status } \\
\hline Single & $6(13)$ & $24(51)$ & $16(34)$ & $1(2)$ & 47 \\
\hline Not Single & $34(28)$ & $41(34)$ & $42(34)$ & $5(4)$ & 122 \\
\hline \multicolumn{6}{|l|}{ Children } \\
\hline No Child & $22(28)$ & $27(34)$ & $30(38)$ & $1(1)$ & 80 \\
\hline One Child & $3(16)$ & $8(42)$ & $7(37)$ & $1(5)$ & 19 \\
\hline $2+$ Children & $15(21)$ & $30(43)$ & $21(30)$ & 4 (6) & 70 \\
\hline \multicolumn{6}{|c|}{ Personal experience with the discovery of unsolicited findings } \\
\hline No & $34(24)$ & $57(40)$ & $46(32)$ & $6(4)$ & 142 \\
\hline Yes & $6(22)$ & $8(30)$ & $12(44)$ & $1(4)$ & 27 \\
\hline Total & $40(24)$ & $65(38)$ & $58(34)$ & $6(4)$ & 169 \\
\hline
\end{tabular}

Note:Chi ${ }^{2}$ statistics showed that the only significant difference concerned the effect of the population variable. ${ }^{\mathrm{a} b}$ and ${ }^{\mathrm{c}}$ indicate that data associated with the same letter are significantly different from one another. Source: own work.

\section{Discussion}

The most important finding in this pilot study was that the participants tended to be in favour of disclosing the discovery of an unsolicited finding in genetic testing, some of them unconditionally, whereas others were more sensitive to patient's wishes, and still others judged appropriateness in relation with the information and the disease. As expected, three different positions concerning the appropriateness of disclosing an unsolicited finding in Medical Genetics were found. A fourth one was also observed. A majority of participants gave priority to the principle of beneficence over the principle of autonomy.

For a quarter of our participants, respecting patients' wishes seemed to be the most important factor, as observed in the literature (Downing et al., 2013; Regier et al., 2015). Respect for patient's autonomy seemed to be essential for them. This position was expressed by $53 \%$ of the professionals, $21 \%$ of the patients and $21 \%$ of people from the general population.
We also found a large group of people who considered that beneficence was more important (Cluster 2) or an intermediate position where beneficence takes precedence over autonomy (Cluster 3). The groups comprised respectively $43 \%$ and $35 \%$ of people from the general population, $38 \%$ and $32 \%$ of patients and $7 \%$ and $40 \%$ of health professionals. This finding could go against the "logical" point of view that it is up to the patient to decide.

The fact that the principle of beneficence took precedence over the principle of autonomy in some conditions had already been found in a recent study by Guedj, Sorum and Mullet (2012) concerning the involuntary hospitalization of patients suffering from psychiatric illness. The vast majority of participants (95\%) agreed that involuntary hospitalization was appropriate when a patient was potentially dangerous for others and for him/herself. They considered that the patient's autonomy could be curtailed if this could have consequences on others' health and wellbeing (for example, their relatives).

Similar results were also found in an even more recent study about breaking bad news to elderly patients: more than a quarter of participants judged that the full truth should be told to patients in all circumstances and a further 36\% of all participants agreed, even if they understood that the physician would inform the patient's family first (Igier, Sastre, Sorum, \& Mullet, 2015).

This position is, sometimes, softened, especially when the unsolicited disease is not actionable (Cluster 3). People may judge it less appropriate to disclose unsolicited findings that are involved in the development of diseases for which nothing can be done in terms of prevention or treatment, probably to avoid psychological problems for the patient, as already found in the literature (Bijlsma et al., 2017; Clift et al., 2015).

A fourth and unexpected position was found: A few participants considered the physician's decision always appropriate. Igier et al. (2015) had already observed this finding in a study, where almost $25 \%$ of participants were of the opinion that elderly people should be told the full truth about bad news in some cases and 
not in others, but depending on the physician's perception of the situation. Such a judgment means that the physician knows what is best for the patient, depending on the case. This group of respondents has often been observed in ethical studies (Guedj, Muñoz Sastre, Mullet, \& Sorum, 2006; Guedj et al., 2012, see also, Sedkaoui \& Mullet, 2016). It is important to note that this group of respondents comprised only 6 participants: 4 patients and 2 people from the general population.

In comparison with other factors, "Prevention/ treatment" has less effect. Ethical issues seem to have more importance than medical conditions with respect to the disclosure of unsolicited findings in Medical Genetics. Future studies, using a larger sample (especially more genetic professionals) should examine whether we would find the same positions with groups that are more comparable in terms of size in each of the three samples and the compositions of the clusters.

It should be noted that unsolicited findings with a low penetrance may also be discovered during the sequencing. In this case, the genetic mutation would make the patient more vulnerable to developing the (multifactorial) associated disease than people who do not have this mutation. As a follow-up to this study, we will therefore propose scenarios concerning low penetrance genetic mutations to determine whether there are any differences in the appropriateness of disclosing this kind of discovery.

\section{Acknowledgements}

The authors deeply thank the persons that accepted to participate at the research. The authors also thank Pr. Mullet for his help and advice on statistics.

\section{References}

Allyse, M., \& Michie, M. (2013). Notso-incidental findings: the ACMG recommendations on the reporting of incidental findings in clinical whole genome and whole exome sequencing. Trends in Biotechnology, 31 (8), 439-441.

Anderson, N. H. (1996). A functional theory of cognition. Mahwah, NJ: Lawrence Erlbaum Associates.

Anderson, N. H. (2016). Information integration theory: Unified psychology based on three mathematical laws. Universitas Psychologica, 15(3). https://doi.org/10.11144/Javeriana.u psy15-3.iitu

Beauchamp, T. L., \& Childress, J. F. (2001). Principles of Biomedical Ethics (5th ed.). Oxford, England: Oxford University Press.

Berg, J. S., Khoury, M. J., \& Evans, J. P. (2011). Deploying whole genome sequencing in clinical practice and public health: meeting the challenge one bin at a time. Genetics in Medicine: Official Journal of the American College of Medical Genetics, 13(6), 499-504. https://doi.org/10.1097/GIM.0b0 13 e318220aaba

Bijlsma, R. M., Wessels, H., Wouters, R. H. P., May, A. M., Ausems, M. G. E. M., Voest, E. E., \& Bredenoord, A. L. (2017). Cancer patients' intentions towards receiving unsolicited genetic information obtained using next-generation sequencing. Familial Cancer, 17(2), 1-8. https://doi.org/ 10.1007/s10689-017-0033-7

Christenhusz, G. M., Devriendt, K., \& Dierickx, K. (2013). To tell or not to tell? A systematic review of ethical reflections on incidental findings arising in genetics contexts. European Journal Of Human Genetics: EJHG, 21(3), 248-255. https://do i.org/10.1038/ejhg.2012.130

Clift, K. E., Halverson, C. M. E., Fiksdal, A. S., Kumbamu, A., Sharp, R. R., \& McCormick, J. B. (2015). Patients' views on incidental findings from clinical exome sequencing. Applied $\mathcal{E}$ Translational Genomics, 4, 38-43. https://doi.org/10.1016/j.atg.2015.02.005

Downing, N. R., Williams, J. K., Daack-Hirsch, S., Driessnack, M., \& Simon, C. M. (2013). Genetics specialists' perspectives on disclosure of genomic incidental findings in the clinical setting. Patient Education and 
Counseling, 90(1), 133-138. https://doi.org/ 10.1016/j.pec.2012.09.010

Green, R. C., Berg, J. S., Berry, G. T., Biesecker, L. G., Dimmock, D., Evans, J. P., ... Jacob, H. J. (2012). Exploring Concordance and Discordance for Return of Incidental Findings from Clinical Sequencing. Genetics in Medicine\#: Official Journal of the American College of Medical Genetics, 14(4), 405-410. https://doi.org/10.1038/gim.2012.21

Green, R. C., Berg, J. S., Grody, W. W., Kalia, S. S., Korf, B. R., Martin, C. L., ... Biesecker, L. G. (2013). ACMG Recommendations for Reporting of Incidental Findings in Clinical Exome and Genome Sequencing. Genetics in Medicine\#: Official Journal of the American College of Medical Genetics, 15(7), 565-574. https://doi.org/10.1038/gim.2013.73

Green, R. C., Lupski, J. R., \& Biesecker, L. G. (2013). Reporting Genomic Sequencing Results to Ordering Clinicians. JAMA\#: The Journal of the American Medical Association, 310(4), 365-366. https://doi.org/10.1001/ja ma.2013.41703

Guedj, M., Muñoz Sastre, M. T., Mullet, E., \& Sorum, P. C. (2006). Do French lay people and health professionals find it acceptable to breach confidentiality to protect a patient's wife from a sexually transmitted disease? Journal of Medical Ethics, 32(7), 414-419. https://doi.org/10.1136/jme.2005. 012195

Guedj, M., Sorum, P. C., \& Mullet, E. (2012). French lay people's views regarding the acceptability of involuntary hospitalization of patients suffering from psychiatric illness. International Journal of Law and Psychiatry, 35(1), 50-56. https://doi.org/10.1016/j.ijlp. 2011.11.010

Haute Autorité de Santé. (2013). Règles de bonnes pratiques en génétique constitutionnelle à des fins médicales (Hors diagnostic prénatal). Retrieved from http://www.has-sante.fr/portail/uploa d/docs/application/pdf/2013-02/regles_de_ bonne_pratique_en_genetique_constitutio nnelle_a_des_fins_medicales.pdf
Hehir-Kwa, J. Y., Claustres, M., Hastings, R. J., van Ravenswaaij-Arts, C., Christenhusz, G., Genuardi, M., ... Robinson, P. N. (2015). Towards a European consensus for reporting incidental findings during clinical NGS testing. European Journal of Human Genetics, 23(12), 1601-1606. https://doi.or g/10.1038/ejhg.2015.111

Igier, V., Sastre, M. T. M., Sorum, P. C., \& Mullet, E. (2015). A Mapping of People's Positions Regarding the Breaking of Bad News to Patients. Health Communication, 30 (7), 694-701. https://doi.org/10.1080/10 410236.2014 .898013

Journal officiel de la République Française. (2013, 27 de mayo). Définissant les règles de bonnes pratiques applicables à l'examen des caractéristiques génétiques d'une personne à des fins médicales. Recuperado de https://www.legifrance.gouv.fr/affichTe xte.do?cidTexte $=$ JORFTEXT0000275136 17

Kalia, S. S., Adelman, K., Bale, S. J., Chung, W. K., Eng, C., Evans, J. P., ... Miller, D. (2017). Recommendations for reporting of secondary findings in clinical exome and genome sequencing, 2016 update (ACMG SF v2.0): a policy statement of the American College of Medical Genetics and Genomics. Genetics in Medicine, 19(2), 249-255. https://doi.org/10.1038/gim.2016. 190

Lemke, A. A., Bick, D., Dimmock, D., Simpson, P., \& Veith, R. (2013). Perspectives of clinical genetics professionals toward genome sequencing and incidental findings: a survey study. Clinical Genetics, 84(3), 230-236. https://doi.org/10.1111/cge .12060

Lohn, Z., Adam, S., Birch, P., Townsend, A., \& Friedman, J. (2013). Genetics professionals' perspectives on reporting incidental findings from clinical genomewide sequencing. American Journal of Medical Genetics Part A, 161(3), 542-549. h ttps://doi.org/10.1002/ajmg.a.35794

Lolkema, M. P., Gadellaa-van Hooijdonk, C. G., Bredenoord, A. L., Kapitein, P., Roach, 
N., Cuppen, E., ... Voest, E. E. (2013). Ethical, legal, and counseling challenges surrounding the return of genetic results in oncology. Journal Of Clinical Oncology: Official Journal Of The American Society Of Clinical Oncology, 31 (15), 1842-1848. https ://doi.org/10.1200/JCO.2012.45.2789

Middleton, A., Morley, K. I., Bragin, E., Firth, H. V., Hurles, M. E., Wright, C. F., \& Parker, M. (2015). Attitudes of nearly 7000 health professionals, genomic researchers and publics toward the return of incidental results from sequencing research. European Journal of Human Genetics, 24, 21-29 https: //doi.org/10.1038/ejhg.2015.58

Ormond, K. E., Wheeler, M. T., Hudgins, L., Klein, T. E., Butte, A. J., Altman, R. B., ... Greely, H. T. (2010). Challenges in the clinical application of whole-genome sequencing. The Lancet, 375(9727), 1749-1751. https://doi.org/10.1 016/S0140-6736(10)60599-5

Ploem, C. (2014). Handling Unsolicited Findings in Clinical Care: A Legal Perspective. European Journal of Health Law, 21(5), 489-504. https://doi.org/10.1163/15718093 $-12341336$

Regier, D. A., Peacock, S. J., Pataky, R., van der Hoek, K., Jarvik, G. P., Hoch, J., \& Veenstra, D. (2015). Societal preferences for the return of incidental findings from clinical genomic sequencing: a discrete-choice experiment. Canadian Medical Association Journal, 187(6), E190. E197. https://doi.org/10.1503/cmaj.140697

Rigter, T., van Aart, C. J. A., Elting, M. W., Waisfisz, Q., Cornel, M. C., \& Henneman, L. (2014). Informed consent for exome sequencing in diagnostics: exploring first experiences and views of professionals and patients. Clinical Genetics, 85(5), 417-422. https://doi.org/10.1111/cge.12299

Roche, M. I., \& Berg, J. S. (2015). Incidental Findings with Genomic Testing: Implications for Genetic Counseling Practice. Current Genetic Medicine Reports, 3(4), 166-176. https://doi.org/10.1007/s401 42-015-0075-9
Sedkaoui, H., \& Mullet, E. (2016). Mapping French people's views on chemical castration of child and adolescent sex offenders. Universitas Psychologica, 15(3). https://doi.org/10.11144/Javeriana.u psy15-3.mfpv,

Shahmirzadi, L., Chao, E. C., Palmaer, E., Parra, M. C., Tang, S., \& Gonzalez, K. D. F. (2014). Patient decisions for disclosure of secondary findings among the first 200 individuals undergoing clinical diagnostic exome sequencing. Genetics in Medicine: Official Journal of the American College of Medical Genetics, 16(5), 395-399. https://d oi.org/10.1038/gim.2013.153

Townsend, A., Adam, S., Birch, P. H., Lohn, Z., Rousseau, F., \& Friedman, J. M. (2012). "I want to know what's in Pandora's Box": comparing stakeholder perspectives on incidental findings in clinical whole genomic sequencing. American Journal of Medical Genetics Part A, 158A(10), 2519-2525. https://doi.org/10.1002/ajmg.a. 35554

van El, C. G., Cornel, M. C., Borry, P., Hastings, R. J., Fellmann, F., Hodgson, S. V., ... de Wert, G. M. W. R. (2013). Whole-genome sequencing in health care. European Journal of Human Genetics, 21 (6), 580-584. https:// doi.org/10.1038/ejhg.2013.46

Wolf, S. M., Annas, G. J., \& Elias, S. (2013). Patient Autonomy and Incidental Findings in Clinical Genomics. Science, 340(6136), 1049-1050. https://doi.org/10.1126/science .1239119

Wolf, S. M., Lawrenz, F. P., Nelson, C. A., Kahn, J. P., Cho, M. K., Clayton, E. W., ... Wilfond, B. S. (2008). Managing incidental findings in human subjects research: analysis and recommendations. The Journal of Law, Medicine Eु Ethics: A Journal of the American Society of Law, Medicine Eु Ethics, 36(2), 219-248, 211. https://doi.org/10.1111/j.174 8-720X.2008.00266.x

Yu, J. -H., Harrell, T. M., Jamal, S. M., Tabor, H. K., \& Bamshad, M. J. (2014). Attitudes of Genetics Professionals Toward the Return of Incidental Results from 
Exome and Whole-Genome Sequencing. American Journal of Human Genetics, 95 (1), 77-84. https://doi.org/10.1016/j.ajhg.2014. 06.004

\section{Appendix}

\section{Results of the ANOVAs for each cluster.}

\begin{tabular}{|c|c|c|c|c|c|}
\hline Cluster and Factor & $d f$ & $M S$ & $F$ & $p$ & $\eta^{2}$ \\
\hline \multicolumn{6}{|l|}{ Autonomy } \\
\hline Decision & 2 & 1760.59 & 36.55 & 0.001 & 0.48 \\
\hline Consent $\mathrm{x}$ Decision & 4 & 11434.62 & 180.08 & 0.001 & 0.82 \\
\hline Prevention/Treatment x Decision & 6 & 134.71 & 5.78 & 0.001 & 0.13 \\
\hline Consent $\mathrm{x}$ Prevention/treatment $\mathrm{x}$ & 12 & 132.65 & 3.41 & 0.001 & 0.08 \\
\hline \multicolumn{6}{|l|}{ Decision } \\
\hline \multicolumn{6}{|l|}{ Beneficence } \\
\hline Consent & 2 & 317.31 & 25.1 & 0.001 & 0.28 \\
\hline Prevention/Treatment & 3 & 111.81 & 9.28 & 0.001 & 0.13 \\
\hline Decision & 2 & 25420.65 & 672.34 & 0.001 & 0.91 \\
\hline Consent $\mathrm{x}$ Decision & 4 & 1112.58 & 46.11 & 0.001 & 0.42 \\
\hline Prevention/Treatment $x$ Decision & 6 & 633.91 & 14.94 & 0.001 & 0.19 \\
\hline $\begin{array}{l}\text { Consent } \mathrm{x} \text { Prevention/Treatment } \mathrm{x} \\
\text { Decision }\end{array}$ & 12 & 116.13 & 3.62 & 0.001 & 0.05 \\
\hline \multicolumn{6}{|l|}{ Non-maleficence } \\
\hline Consent & 2 & 182.72 & 12.91 & 0.001 & 0.18 \\
\hline Decision & 2 & 3593.38 & 85.83 & 0.001 & 0.60 \\
\hline Consent $\mathrm{x}$ Prevention/Treatment & 6 & 158.05 & 6.69 & 0.001 & 0.10 \\
\hline Consent $\mathrm{x}$ Decision & 4 & 5013.88 & 123.88 & 0.001 & 0.68 \\
\hline Prevention/Treatment $\mathrm{x}$ Decision & 6 & 1454.73 & 23.41 & 0.001 & 0.29 \\
\hline $\begin{array}{l}\text { Consent } \mathrm{x} \text { Prevention/Treatment } \mathrm{x} \\
\text { Decision }\end{array}$ & 12 & 287.53 & 4.69 & 0.001 & 0.08 \\
\hline \multicolumn{6}{|l|}{ Always appropriate } \\
\hline Consent & 2 & 10.95 & 0.51 & ns & 0.09 \\
\hline Prevention/Treatment & 3 & 206.9 & 1.39 & ns & 0.22 \\
\hline sion & 2 & 127.23 & 2.8 & ns & 36 \\
\hline
\end{tabular}

\section{Notes}

* Research article. 